\title{
Legalización de las drogas: entre las políticas de seguridad y la salud pública*
}

\author{
Profesora titutar del programa de Ciencia Política de la \\ Universidad de los Andes, Colombia
}

\author{
Arlene B. Tickner, Ph.D.**
}

En esta oportunidad voy a hablar de tres temas que podríamos numerar así: primero, la securitización de las políticas antidrogas en términos conceptuales ${ }^{1}$, segundo las drogas y el aporte que recibió América Latina de los Estados Unidos y por último una breve reflexión sobre hasta qué punto podemos mejorar los métodos de cambio de paradigmas, frente a lo cual quisiera ser optimista, pero más bien soy reservada.

En relación al primer punto, sobre la securitización de las drogas, es importante antes que todo tratar de rastrear el origen del problema de las drogas. A mi parecer, todo inicia, más o menos, cuando se relaciona a las drogas con un mal moral y cuando se percibe como una amenaza para la seguridad. Yo no estoy en desacuerdo con las anteriores afirmaciones. De hecho, en la política de los Estados Unidos, o en el trasfondo de la "mentalidad de guerra contra las drogas", estos dos componentes se ven juntos y parecen indisociables: "las drogas son malas y las drogas son una amenaza para la seguridad".

\footnotetext{
El presente artículo recoge el discurso dictado por la profesora Arlene B Tickner durante el foro: "Legalización de las drogas: entre las políticas de seguridad y la salud pública”. Este foro fue organizado por la Facultad de Derecho y Ciencias Sociales y el Departamento de Estudios Políticos de la Universidad Icesi de Cali.

1 Para profundizar sobre este punto, buscar TICKNER, Arlene B. (2004). "La securitización de la crisis colombiana: bases conceptuales y tendencias generales”. En: Colombia Internacional, No. 60, pp. 12-35. Bogotá D.C: Facultad de Ciencias Sociales, Departamento de Ciencia Política, Universidad de los Antes. Consulta realizada desde http://colombiainternacional.uniandes.edu.co/view.php/439/view.php
} 
Pero lo que quiero sugerir es que a esa combinación, es a la que podemos llamar como la "securitización de las drogas". El uso del término securitización sugiere todo un bagaje conceptual que se conoce como la teoría de la securitización y que se estudia desde el campo de las relaciones internacionales. Esta teoría lleva ya algún tiempo desarrollándose, y lo que sugiere es que esta idea no actúa exclusivamente en función de las drogas, sino a todo lo que se puede identificar como una amenaza a la seguridad. Pero no solo porque consideremos que $\mathrm{X}$ problema sea una amenaza y que a manera de solución se procure su securitización, sino más bien lo que analiza es lo que hay detrás de esa declaratoria que puede encontrase en la siguiente pregunta: ¿puede esta amenaza contener algún tipo de implicación política? Si intentamos responder a esa pregunta, podremos entender lo que quiero recalcar.

La idea de securitización sugiere distintos tipos de problemas, bien sean las drogas, la pobreza, el sida, o muchos otros. Esto no significa que sean amenazas per se, sino que se convierten en tales mediante el uso del discurso, lo que es comparable a los discursos de drogas contra el alcohol y el tabaco. Todos sabemos todo tipo de cosas sobre el alcohol y el tabaco, hasta que son muchos más nocivos, que cobran muchas más vidas humanas que quien consume no solo marihuana sino todas las drogas en su conjunto, y sin embargo el tabaco y el alcohol no se declaran amenazas a la seguridad. Hoy en día eso está cambiando mucho, al menos al alcohol sí se le está tratando como amenaza.

Como ejemplo de cómo cambian los discursos, se me viene a la cabeza el uso del opio. En tiempos no tan pasados se usaba en los medicamentos de los niños para la tos, pues era considerado uno de los mejores remedios para calmarla. Entonces es muy importante entender la securitización, antes que una "amenaza" en sí misma, pues esta se convierte en tal, mediante su evocación a un discurso en particular. Es más, plantear la idea de las FARC como grupo terrorista está también vinculado a la emergencia de un discurso. Las FARC se convierten en terroristas en un día y a una hora determinada: el 21 de febrero del 2002, más o menos a las 7:30 p.m., si mal no recuerdo. En ese momento, el presidente Pastrana sale en televisión para anunciar la finalización del proceso de negociación en el Caguán, y esa noche declara por primera vez públicamente: "ustedes, señores de las FARC, son un grupo terrorista”. 
Ahora, imaginen todo lo que siguió después de la normalización de su declaración como grupo terrorista; luego durante el gobierno de Álvaro Uribe se negó de tal manera la existencia de un conflicto armado en Colombia llegando hasta tal punto que se borraría el termino de conflicto armado de todo documento público que circularía en el exterior, y además, los funcionarios representantes de Colombia en el exterior tuvieron prohibido hablar sobre el tema: conflicto armado en Colombia.

Todo esto no es gratuito, es producto de lo que podría denominarse el proceso de securitización y sus efectos. Nombrar algo como "amenaza a la seguridad", como ha sucedido en el caso de las drogas, tiene un efecto político triple. Primero, todo lo relacionado al asunto se construye con carácter excepcional y extraordinario, es una cuestión de vida o muerte, algo que amenaza a la seguridad. De lo cual se desprende un segundo punto, y es que este carácter extraordinario, excepcional, permite legitimar, por parte del Estado, el uso de cualquier mecanismo que sea necesario para enfrentarlo, sobre todo de carácter militar. Es decir: securitizar algo repercute naturalmente en la adopción de ciertas estrategias militares "necesarias" para hacer frente al problema, debido a su carácter de extraordinario y excepcional. Tercero y no menos preocupante, lo que hace esta declaratoria al catalogar algún aspecto como "amenaza" es alejar la temática de los espacios públicos del debate, y estos deberían hacer parte de cualquier problema en una democracia.

Como ejemplo de todo esto, valdría la pena recordar el Plan Colombia del año 1999. Cuando se anuncia todos los medios reportan a la opinión pública que Estados Unidos ha aprobado un paquete de ayuda muy importante para el país, de enormes cantidades de millones de dólares. Entonces quedó entredicho que ya el problema estaba resuelto en el país. Pero si analizamos bien la situación, nos daremos cuenta de que el Plan Colombia no tuvo realmente ningún tipo de discusión pública a su alrededor y, quisiera sugerir, no fue solo por desinterés de la opinión pública colombiana sobre temas internacionales, lo que es no es algo inusual ${ }^{2}$, sino que también tiene que ver con la securitización misma

2 En el marco del proyecto que lleva como nombre Las américas y el mundo: opinión pública y política exterior, coordinado por la División de Estudios Internacionales del Centro de Investigación y Docencia Económicas (CIDE) de México, los profesores Arlene Tickner y Felipe Botero en la presentación los resultados obtenidos de las encuestas aplicadas en Colombia en el 2008 y 2010 obtuvieron que el 53\% y 52\% de los colombianos encuestados, respectivamente, se interesan "mucho" o "algo" por las noticias sobre las relaciones de Colombia con el exterior. Ver: 
de todo lo que ha sido el manejo del tema de las drogas por los gobiernos en el país, que esencialmente obstruye cualquier debate público. Y si uno trata de debatir públicamente el tema, entonces puede llegar a ser tildado de terrorista, al menos durante el gobierno de Álvaro Uribe. Con esto vemos, que la securitización le permite también al Estado estigmatizar ciertas prácticas y a quienes tratan de destapar el tema con el fin de plantearlo en un espacio público.

En relación al segundo punto (que tiene que ver con el tema de las drogas y la política exterior estadounidense) justamente son los Estados Unidos el principal responsable de la "securitización de las drogas" y de la guerra en su contra, sobre todo a partir del presidente Nixon y con más claridad en relación al contexto internacional, desde los gobiernos de la década de 1980. Esta temática puesta en el contexto de la Guerra Fría se convertiría en el tema principal de seguridad en la política exterior de los Estados Unidos respecto a América Latina. Desde ese momento se habla de la securitización del tema, del cual todos hemos sido testigos. Así se da un traslado de mentalidad hacia la guerra contra las drogas en toda América Latina, siendo Colombia uno de los mejores y más triste ejemplos. Como todos conocemos más o menos en que consiste esta política, yo quisiera tratar algunos elementos de sus lógicas principales y de sus efectos negativos, más allá del obvio fracaso de la guerra contra las drogas, idea que todos, o espero, compartimos y que está muy bien documentado en varios textos académicos.

El primer efecto de esta mentalidad de securitización de la guerra contra las drogas, es obviamente el uso de estrategias militarizadas para hacer frente a un problema que debe ser tratado yo creo que desde sus múltiples caras. En esto la dicotomía falsa de la legalización o prohibición no ha ayudado en lo más mínimo, la dicotomía normal y el lenguaje dicotómico y binario imposibilitan el desarrollo de cualquier alternativa política que no sea legalizar o "echar bala".

Segundo, la estrategia de estados unidos ha dado vueltas en el uso de lo que podemos llamar diplomacia coercitiva, frente a países diferentes de la región, con el fin de 
reforzarlos para adoptar ciertas medidas que "solucionen o no el problema". El presidente Samper ha sufrido de sobra estas implicaciones, pero quisiera dictar un ejemplo no solo de su gobierno, sino de otros, que estén en el proceso de la certificación que en buena hora fue ya eliminado. Estados unidos durante años se auto atribuyó el derecho de "certificar" de forma unilateral a todos los países del mundo, no solo a los de América Latina, en cuanto a su cumplimiento con las políticas estadounidenses de luchas contra las drogas -el único que no se certificaba era los Estados Unidos, evidentemente, pues hubiese sido descertificado en el caso de haberse aplicado sus propias reglas. ¿Y ante una descertificación o una certificación condicionada que pasaba?, ¿y qué pasa todavía hoy cuando Estados Unidos le diga a cierto país: "no me gusto lo que usted hizo o no hizo"? Pues Estados Unidos tiene una lista de condiciones que espera, el país en cuestión cumpla en sus políticas antidrogas, para poder reestablecer o restaurar la buena relación, y en el peor de los casos amenazan con quitar ciertas prerrogativas al país en cuestión a manera de presión para que adopten estas medidas.

En el caso de Colombia, durante el gobierno del presidente Samper se dio esta certificación y vino acompañada de la amenaza de retirarle al país los beneficios arancelarios, producto del reconocimiento de responsabilidad compartida. Este es un solo episodio, pero hay muchos, en general se trata de una política de opresión hacia los países de la región, para que adopten las medidas estadounidenses.

Tercero, una política estadounidense frente a las pocas en la región trae consecuencias. Se parte de unas relaciones de "tú a tú" -entre comillas- porque estados unidos nunca interactúa de tú a tú con nadie y mucho menos con los países de América latina. Estamos hablando de relaciones bilaterales con distintos países de la región que han tendido - en lo que yo opino- a obstaculizar la cooperación directa entre estos países y peor, ponerlos a competir entre sí por los recursos provenientes de Estados Unidos para luchar contra las drogas, un ejemplo de esto es precisamente la llamada iniciativa regional Andina que les habla.

El plan Colombia sirvió como una especie de contentillo de los países andinos que iban a recibir algunos de los efectos de su implementación. Pero otro caso más reciente es el del presidente de Guatemala, MOLINA. "Molina era de extrema derecha en el pasado político de Guatemala" y hoy en día, curiosamente, está haciendo un llamado por la lega- 
lización. Yo pues, no tengo por qué dudar de la genuinidad de su discurso, pero creo que leyendo más allá de lo que dice, uno puede ver en su solicitud, una especie de "patada de ahogado" que pretende llamar la atención de Estados Unidos, con el fin de que desembolse el dinero que necesita Guatemala para luchar contra las drogas y sobre todo contra la presencia del crimen organizado en el país, que ha generado para el Estado una situación que ya es inmanejable. Guatemala siendo como honduras, dos países con las tazas de homicidio más altas del mundo, con un nivel de inseguridad ciudadana altísimo y ¿hasta qué punto el discurso produjo un cambio? A la política no le corresponde, por efecto, llamar la atención, y creo que esto refleja un poco la lógica perversa de no cooperación y de competencia entre sí, que produce la política antidrogas de Estados Unidos.

Además del fracaso rotundo de la guerra contra las drogas como tal, que no reduce el consumo y aumenta los precios de las drogas, para mí el efecto más nocivo es la estrategia que multiplica tanto los lugares como los actores involucrados en el negocio de las drogas, esto es básicamente lo que llamamos el efecto globo. Lo que ha hecho la política antidroga desmontando carteles, erradicando cultivos, es fragmentar y esparcir el negocio. Colombia que era un país donde los cultivos ilícitos se concentraban en pocos departamentos, se volvió al cabo de pocos años en un país en el cual muchos departamentos tenían cultivos de coca. En términos de tráfico, los dos grandes carteles de la droga en Colombia tuvieron lugar-como todos bien sabemos- al ingreso de una cantidad de distintos tipos de actores, los llamados "babi", los paramilitares, los guerrilleros, los mexicanos, y hoy en día los norteamericanos y algunos caribeños. Muchos de los nuevos jugadores del negocio de las drogas, ante las estrategia de la guerra contra las drogas, pagan las transacciones en especie, entonces los países de tránsito (centro América y el Caribe) reciben pagos en cocaína, lo cual los convierte en potenciales traficantes a futuro, entonces en términos generales el fracaso tiene múltiples caras.

Finalmente el tercer y último punto, las voces de cambio de las que puedo hablar muy por encima. la pregunta que tengo es, si un alto porcentaje de la opinión mundial cree que la guerra contra las drogas es un fracaso o ha sido un fracaso ¿Por qué sigue en pie? Tenemos una cantidad de indicios de cambio que están muy bien rescatados en el libro: legalización de la marihuana para usos medicinales en dos 
estados de los Estados Unidos, diferentes mecanismos de despenalización no solo en Estados Unidos, sino en países como: Holanda, Portugal, Colombia y otros países de la región. También se tiene la legalización de la dosis personal de ciertas sustancias, esquemas alternativos de manejo de cultivos como ocurre en Bolivia, que tiene un experimento más reciente de reducción de daños en relación con los cultivos de coca, mediante varios esquemas de negociación para el involucramiento de los campesinos cultivadores en los programas de radicación. Por otra parte están los reclamos de varios presidentes de América Latina, comenzando con Santos - presidente de Colombia- para que se haga una reevaluación de los logros y fracasos que daría la lucha contra las drogas. También está una nueva política de drogas de Obama, aunque yo veo muy difícil imaginar que vaya más allá de la marihuana; para mí la marihuana evidentemente se va a legalizar tarde o temprano. No veo que esto signifique que otras sustancias como la cocaína se vayan a legalizar y en este punto creo que no va a ocurrir. Primero que todo pese a que la opinión publica cree que la guerra actual ha sido un fracaso, se opone radicalmente a que haya legalización para sustancias distintas a la marihuana, una pregunta a la opinión pública mundial ¿Qué pensaría de legalizar por ejemplo la cocaína? Las opiniones todavía son bastante mezcladas, no hay un consenso tan fuerte frente a cocaína y menos frente a otras sustancias como la que hay frente a la marihuana.

Por otra parte, el presidente Samper ha mencionado algunos países que sencillamente son renuentes a un cambio de paradigmas, Estados Unidos es solo uno de ellos, Rusia y China -dos potencias en el sistema internacional- se oponen radicalmente a toda forma multilateral que pretenda cualquier discusión de flexibilización de la política, como también lo hacen los países islámicos. Como él ha señalado (presidente Samper). ¿Hasta qué punto se pueden cambiar las formas multilaterales? Hay cierto escepticismo, y pensando en nuestra religión y aquí termino, creo que es muy difícil imaginar un cambio dramático teniendo en cuenta la crisis de seguridad que la guerra contra las drogas se ha encargado de profundizar. Esto va a sonar un poco paradójico: la guerra contra las drogas ha incrementado la crisis de seguridad ciudadana, no solo en Colombia, sino en centro América, en México ni hablar, varios países del caribe, Sudamérica en algunos casos y Paraguay. 
Mi argumento es, que la misma crisis de seguridad que la guerra contra las drogas se ha encargado de profundizar, dificulta que los gobiernos tomen la decisión de hacer un cambio de rumbo, precisamente porque la crisis, genera en la población una exigencia de mano dura. Esto lo vemos en varios países de la región, donde los homicidios y la criminalidad están disparados. Argumentar que hay que despenalizar, es una apuesta que hoy en día es muy difícil de hacer para cualquier político, entonces yo le pregunto al expresidente Samper, si nos puede comentar que piensa de eso, ¿cómo reemplazar la lógica actual cuando estamos en medio de semejante explosión de seguridad en la región?

Ahora sí termino, gracias. 